\title{
Retrospect and Prospect of the Research into Chinese Hezhe Nationality
}

\author{
Yan Sun \\ Faculty of Arts, Southwest University, Chongqing, China \\ Email: cxxs0828@126.com
}

Received 12 June 2014; revised 27 July 2014; accepted 12 August 2014

Copyright @ 2014 by author and Scientific Research Publishing Inc.

This work is licensed under the Creative Commons Attribution International License (CC BY).

http://creativecommons.org/licenses/by/4.0/

(c) (i) Open Access

\begin{abstract}
Through the scientometric analysis of these sample documents is related to the ten-year academic researches on Chinese Hezhe nationality, it could find out that the continuous study in this field provides a solid intelligence support for the development of Chinese ethnic minorities. However, problems still exist for the present, that is, the research content need to be deepened while the research perspective is expanded. And what's more, the lack of the comparative analysis and the empirical research also should be given more attention in the future study. This essay would like to focus on the existing disadvantages by strengthening the problem consciousness which can help improve the researchers' concern over the Hezhe nationality, reinforce the comparative analysis and empirical research, enhance the comprehensive analysis of multi-disciplinary and multi-perspective and constantly promote the further development of the research in this field.
\end{abstract}

Keywords

Hezhe Nationality, CNKI Journal Data, 2003-2013, Scientometric Analysis

\section{Introduction}

National unity continuously performs as the mainstream of the authorities in the historical development of China in the past decades for "National Equality, National Unity and Mutual Prosperity of All Nations" is China's basic principle guiding relationships between nationalities in accordance with the fundamental interests of people of all nationalities, which has been advocated wholeheartedly by the Chinese people. It has been taken as the evergreen-topic over the years in academia, relating to the researches on national history, the ethnic relations as well as the ethnic fusion so on and so forth. Researches on the Hezhe nationality stemmed from the 1930s, whereas its domestic academic researches actually began at the 1980s which was later than the relevant circles in a Russia research for nearly a century due largely to the influences over the natural and social factors, as their 
frontier locations and inconvenient traffic. In the 21th century, researchers have achieved considerable success in the field of the Hezhe natinality although infused with some unsatisfied results. In order to master the context of national development better and promote the national prosperity and development, this paper takes the scientometric analysis as the way to sort out and analyze Hezhe metrology research area in recent years, under the guidance of Chinese national policy. While in advancing the study of Chinese ethnic minorities, this paper constantly summarizes Hezhe research findings and reflects their defects so as to provide a reference for the future development and prosperity of the nation.

\section{Data Source and Research Method}

\subsection{Sample Retrieval Sources}

China National Knowledge Infrastructure (CNKI) is an important academic journal platform for academic research industries at home and abroad. At present, CNKI contains a total of 7556 different kinds of periodicals, including a high rate of $99 \%$ of important evaluative database source journals such as the core journals, conference papers [1]. This paper sets the time from January 1, 2003 to December 31, 2013 extracting keywords of "Hezhe" and the "Hezhe nationality", and gets 869 relevant papers in which the invalid samples have been excluded. Such retrieval methods aim at narrowing the statistical error probability and making the sampling samples meet the study criteria. Thereby it could accurately grasp the overall situation and development trend of this research and increase its scientific rigor and credibility.

\subsection{Research Method}

Ethnological studies as a conventional method is being applied to the current status of the national study. Combing though the documents over the years, this paper classifies and does other quantitative analysis. In order to determine the reliability of the available data, this paper uses mathematical statistical methods to make the credible conclusions and forecasts. Such study method belongs to the scientometrics (referring to the basic, exploratory, pioneering science research method, usually in line with the latest scientific and technological achievements to precisely define and achieve measurement, and provides reliable scientific measurement theory and practice technology for technological development). In the entire sample analysis, this paper sets five dimensions, "total distribution", "keyword distribution", "research-level distribution”, "subjects distribution", and "citations distribution". Based on these five dimensions, it will get relatively objective and accurate conclusions by describing and analyzing the research samples.

\section{Basic Situation and Quantitative Description}

\subsection{Research Distribution over the Decade}

Since the 1980s, it has gotten great achievement in the field of Hezhe research, as a total of 1535 pieces of papers. Although it is not fully studied as well as other national minorities, it still has high scientific value on the foundation of Hezhe research. This paper selects a total of 869 samples among the papers published for the research during the past decade, while their specific statistics and trends as shown in Table 1, Figure 1.

The research progress could be clearly seen from Table 1 and Figure 1. In 2003, there were only 27 pieces of papers correlating closely with Hezhe researches, accounting for only $3.11 \%$ of the total sample. During the consecutive ten years, it shows an undulating curve, but the overall study presents a gradually increasing trend. From 2003 to 2007, the Hezhe studies reach a total of 254, especially 69 papers in 2007 getting an increase of $1.56 \%$ within five years, which indicate that Hezhe academic research in the country has been given a relatively sustained attention. The Report of the $17^{\text {th }}$ National Congress of the Communist Party of China in 2007 stressed the importance of that "giving full consideration for the development of Tibet, Xinjiang and other region of the ethnic groups who have comparative less population". This policy provides guidance for the academic study of the ethnic groups' development issues. However in 2008, there were only 56 papers by 6.44 percentages of the total samples, which indicates a downward trend for the geological disasters taken in the year and all the nations were fighting against the natural disasters. In the next several years, the amount of research results continued to 
Table 1. 2003-2013 Hezhe research statistics.

\begin{tabular}{ccccccccccccc}
\hline Year & 2003 & 2004 & 2005 & 2006 & 2007 & 2008 & 2009 & 2010 & 2011 & 2012 & 2013 & Total \\
\hline Number & 27 & 44 & 46 & 57 & 69 & 56 & 99 & 119 & 92 & 124 & 136 & 869 \\
Ratio & $3.11 \%$ & $5.06 \%$ & $5.29 \%$ & $6.56 \%$ & $7.94 \%$ & $6.44 \%$ & $11.39 \%$ & $13.70 \%$ & $10.59 \%$ & $14.27 \%$ & $15.65 \%$ & $100 \%$ \\
\hline
\end{tabular}

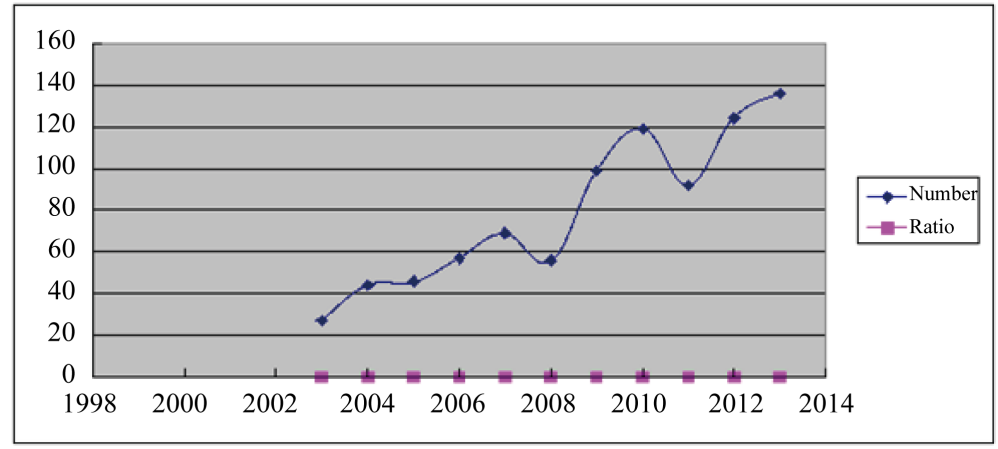

Figure 1. 2003-2013 trends for Hezhe research statistics.

be a rising trend, marking that it is a new stage of Hezhe study after a short brief of the adjustment, and the academic studies on started afresh with high heat.

\subsection{Keywords Distribution}

Keywords refer to a reference extracted from the titles, the contexts or abstracts to generalize the text's subject content and own substantive meaning itself [2]. Keywords can not only be a single word, a phrase, a short sentence a question but also include numbers and kinds of symbols [3]. In academic research, keywords can accurately reflect the characteristics of the research topics, therefore, in a specific research field a set of keywords could represent its trend, features and development sequence. Thus with Classification and Statistic, a scientific study can be made to predict and to improve the accuracy of the study. This paper collects 2963 keywords from sample researches including repeated ones. The Top 20 is chosen to analyze, as shown in Table 2:

Table 2 shows that the most frequently used 20 keywords are not highly used as anticipated. "Yimakan", known as Hezhe epic, is used 156 times ranking the top place. Yimakan, the song of Hezhe, actually is sung by singers the praises of the heroes and battles in history in free verse. It is a widely circulated mythological epic. The amount of "ethnic culture", "music" and other correlative keywords accounts for $11.0 \%$, with a total number of 327 times, which could be seen the highly valued research in the field of art. It is also found that most of these keywords are expanded from Hezhe intangible cultural heritage, such as fish skin clothes, music, Shaman, song of Jia Kuo Ling, Hezhe language, fishing and hunting culture, ethnic literature, etc. However, this spiritual wealth is to be built on the basis of the material, so that the rapid economic development in Hezhe ethnic minority areas benefit from the high-speed developed tourism and tourism-based economy.

\subsection{Subjects Distribution}

As one part of Chinese ethnic research, the study of Hezhe is closely related to national survival and development and involved in comprehensive multi-disciplinary topics. According to subject attribution, this paper categorizes 2003-2013 academic research papers, as shown in Table 3.

As shown in Table 3, subjects distribution of Hezhe research covers widespread. Analyzing by the perspective of subjects correlation, ethnonymics and artistics could be regarded as the main trends in science research, which accounts for $36.2 \%$ of the total samples. This situation is more in line with the substance of the national study. At the same time, according to the research findings, the study is still confined in exploring Hezhe research itself, lacking of cross-analysis and cross-theory thinking, despite its extensive range of subjects. The research findings of ethnonymics and artistics rised sharply between 2012 and 2013, which had 156 papers and 158 papers respectively accounting for $18.0 \%$ and $18.2 \%$. In addition, the research on the historical origins, development and other aspects of the Hezhe nationality, also has been a hot research area, along with 128 findings, 
Table 2. 2003-2013 Top 20 keywords distribution for Hezhe research.

\begin{tabular}{cccccc}
\hline Num & Keywords & Papers & Num & Keywords & Papers \\
\hline $\mathbf{1}$ & Yimakan & 156 & $\mathbf{1 1}$ & Protection & 72 \\
$\mathbf{2}$ & Music & 126 & $\mathbf{1 2}$ & Inheritance & 72 \\
$\mathbf{3}$ & Hezhe language & 123 & $\mathbf{1 3}$ & Shaman & 72 \\
$\mathbf{4}$ & Fish skin & 117 & $\mathbf{1 4}$ & Education & 54 \\
$\mathbf{5}$ & Intangible cultural heritage & 108 & $\mathbf{1 5}$ & Economic development & 54 \\
$\mathbf{6}$ & Sport & 93 & $\mathbf{1 6}$ & Cultural change & 48 \\
$\mathbf{7}$ & Clothes & 93 & $\mathbf{1 7}$ & Development & 45 \\
$\mathbf{8}$ & Ethnic culture & 90 & $\mathbf{1 8}$ & Countermeasures & 45 \\
$\mathbf{9}$ & Hunting and fishing culture & 90 & $\mathbf{1 9}$ & Ethnic literature & 45 \\
$\mathbf{1 0}$ & Tourism & 75 & $\mathbf{2 0}$ & Song of Jia Kuo Ling & 42 \\
\hline
\end{tabular}

Table 3. 2003-2013 subjects distribution for Hezhe research.

\begin{tabular}{|c|c|c|c|c|c|c|c|c|c|c|c|c|c|}
\hline Year & 2003 & 2004 & 2005 & 2006 & 2007 & 2008 & 2009 & 2010 & 2011 & 2012 & 2013 & sum & Ratio \\
\hline artistics & 6 & 5 & 6 & 6 & 13 & 9 & 22 & 19 & 18 & 25 & 27 & 156 & $18.0 \%$ \\
\hline ethnonymics & 2 & 10 & 7 & 13 & 19 & 12 & 19 & 18 & 14 & 21 & 23 & 158 & $18.2 \%$ \\
\hline culture & 2 & 0 & 1 & 1 & 3 & 3 & 10 & 11 & 12 & 13 & 17 & 73 & $8.4 \%$ \\
\hline pedagogics & 0 & 2 & 0 & 0 & 0 & 2 & 10 & 12 & 7 & 7 & 15 & 55 & $6.3 \%$ \\
\hline Tourism & 2 & 6 & 6 & 8 & 4 & 6 & 7 & 12 & 10 & 11 & 13 & 85 & $9.8 \%$ \\
\hline politics & 2 & 3 & 9 & 11 & 8 & 8 & 5 & 12 & 8 & 12 & 13 & 91 & $10.5 \%$ \\
\hline history & 2 & 9 & 8 & 11 & 12 & 9 & 14 & 21 & 11 & 19 & 12 & 128 & $14.7 \%$ \\
\hline literature & 2 & 0 & 2 & 1 & 0 & 2 & 5 & 3 & 4 & 7 & 8 & 34 & $3.9 \%$ \\
\hline linguistics & 5 & 3 & 2 & 2 & 3 & 2 & 3 & 1 & 3 & 2 & 4 & 30 & $3.5 \%$ \\
\hline sociology & 0 & 0 & 0 & 0 & 0 & 0 & 0 & 0 & 1 & 1 & 1 & 3 & $0.3 \%$ \\
\hline religion & 2 & 2 & 2 & 3 & 0 & 0 & 0 & 0 & 1 & 2 & 0 & 12 & $1.4 \%$ \\
\hline medicine & 1 & 1 & 1 & 0 & 2 & 1 & 0 & 2 & 0 & 1 & 1 & 10 & $1.2 \%$ \\
\hline other & 1 & 3 & 2 & 1 & 5 & 2 & 2 & 3 & 3 & 5 & 7 & 34 & $3.9 \%$ \\
\hline sum & 27 & 44 & 46 & 57 & 69 & 56 & 97 & 114 & 92 & 126 & 141 & 869 & $100 \%$ \\
\hline
\end{tabular}

accounting for $14.7 \%$.

\subsection{Research-Level Distribution}

Analyzing the contents of the documents, this paper finds that Hezhe researches have a broad vision involving diverse disciplines. In order to facilitate the study of this subject, it is divided into four levels. First it is the theoretical study which is an abstraction or inferred analysis of research for the purpose of the task, the human condition, and social development and education issues. The second is the experience study. It is a direct connection with the outside world through a variety of senses to obtain a preliminary understanding of the surface of the objective things. The third one is the comparison study of different countries, or the same country with different ethnic groups or regions which contains certain or some social phenomena. The last one is the empirical research which is to demonstrate the proposed theoretical assumptions through interviews, questionnaires, fieldwork, laboratory and other methods in order to collect materials and analyze data. According to these four levels, this paper classifies Hezhe researches as shown in Table 4.

The figures in the table clearly reflect the differences among each research levels. The experience study is the mainstream of Hezhe research. It is in a more balanced development in each year with a total of 383 papers accounting for $44.1 \%$. The second followed is the theoretical study and in-depth analysis, with a total of 373 accounting for $42.9 \%$, indicating that over ninety percent of the country's major research achievements related 
Table 4. 2003-2013 research-level distribution for Hezhe research.

\begin{tabular}{cccccccccccccc}
\hline year & $\mathbf{2 0 0 3}$ & $\mathbf{2 0 0 4}$ & $\mathbf{2 0 0 5}$ & $\mathbf{2 0 0 6}$ & $\mathbf{2 0 0 7}$ & $\mathbf{2 0 0 8}$ & $\mathbf{2 0 0 9}$ & $\mathbf{2 0 1 0}$ & $\mathbf{2 0 1 1}$ & $\mathbf{2 0 1 2}$ & $\mathbf{2 0 1 3}$ & sum & ratio \\
\hline Theoretical study & 6 & 18 & 15 & 22 & 32 & 30 & 49 & 51 & 46 & 43 & 61 & 373 & $42.9 \%$ \\
Experience study & 18 & 25 & 24 & 29 & 30 & 30 & 42 & 40 & 41 & 51 & 53 & 383 & $44.1 \%$ \\
Comparison study & 7 & 0 & 7 & 4 & 10 & 6 & 2 & 4 & 5 & 6 & 3 & 54 & $6.2 \%$ \\
Empirical research & 3 & 6 & 5 & 4 & 9 & 7 & 3 & 5 & 9 & 3 & 5 & 59 & $6.8 \%$ \\
\hline
\end{tabular}

to these two aspects. Compared with the first two studies, the last two research levels have less research findings, with a sum of 103 papers accounting for $13.0 \%$. Based on the above comparison of the data, it could be found that first, it is the maked lack of sufficient data and case analysis in the process of study; secondly, the advanced experience and methods are not widespread used in study process. It supposes to rise to a higher level if it continues to improve and strengthen in Hezhe research.

\subsection{Citations Distribution}

According to the research paper citations, it can identify that the quality and vitality of the scientific papers could be evaluated through the higher frequency and longer time-span one paper has been cited, that is, the greater role and impact it plays in scientific development [4]. At the same time it means that if it has been got attention and recognition by experts and scholars. To this end, this paper analyzes samples according to their cited frequency of the research papers, as follows in Table 5.

It could be seen from the content of the cited papers that the influences of Chinese Hezhe research mainly focus on these two aspects. First it is the life and production of the Hezhe nationality. As a minority with weak productivity living in China's frontier, Hezhe people still live a relatively backward life and hold the status of primitive tribes. For the construction of an ethnic autonomous area and the goal of prosperity of all nations, the government implements effective policies, improving the production and living infrastructure and exercising wholeheartedly in their interests in order to improve Hezhe local production and people's life quality. Nearly a decade of research shows that academia make many feasible measures and suggestions which provide booster for the social process of Hezhe civilization in order to improve the quality of life of Hezhe people from the original ecological point of view and to accelerate economic development in ethnic autonomous area. The second one is the protection and inheritance of Hezhe's intangible cultural heritage. The intangible cultural heritage indicates that its inheritance is not in material form, but in oral or other intangible cultural content, including kinds of social practice, performance, manifestation, knowledge and skills and their related instruments, objects, artifacts, cultural spaces and so on. Compared with the tangible cultural heritage, the intangible cultural heritage reflects the history and culture of human society from a higher level. It is not only an important resource for the study of human society and its historical and cultural context of the development, but also a kind of reflection of cultural diversity and source of human creativity. However, in the context of globalization, modernization and urbanization, the protection of Chinese intangible cultural heritage of Chinese ethnic faces serious challenges. At present, the academic research through case analysis to a certain extent reflects the status quo of Hezhe's intangible cultural heritage protection, providing countermeasures and suggestions from different perspectives and making a great contribution on the protection work.

\section{Conclusions and Suggestion}

\subsection{Comments on the Status of Academic Research Results}

In order to promote the scientific development of the cause of the Party and the state, and provide a solid theoretical foundation and intelligence support for national research, it should be comprehensively and systematically summarized and reviewed the current academic research and learn from each other. Over the ten-year study of Hezhe, its research achievements and varied research methods could be obvious to see that the ethnic research level has reached towards a higher level. However, through quantitative analysis and Objective description, some problems needed to be improved pressingly could be found. 
Table 5. 2003-2013 top 10 cited frequency for Hezhe research.

\begin{tabular}{|c|c|c|c|c|c|}
\hline & Author & Title & Journal & Date & Times cited \\
\hline 1 & HE Jun-fang & $\begin{array}{l}\text { Inter-Ethnic Marriages of Hezhe People: a Typical } \\
\text { Investigation on Inter-Ethnic Marriages of Hezhe } \\
\text { People in Jiangjinkou Township of Hezhe Nationality } \\
\text { of Tongjiang City }\end{array}$ & $\begin{array}{l}\text { Journal of the Central } \\
\text { University for Nationalities }\end{array}$ & 04-03 & 22 \\
\hline 2 & $\begin{array}{l}\text { ZHANG } \\
\text { Hong-yu }\end{array}$ & $\begin{array}{l}\text { Formation and transition of traditional sport of Hezhe } \\
\text { nationality }\end{array}$ & Journal of Physical Education & $09-4$ & 18 \\
\hline 3 & CHEN Peng & $\begin{array}{l}\text { Research on the Hezhen New Manchuria of Northeast } \\
\text { Area in Early Qing Dynasty }\end{array}$ & $\begin{array}{l}\text { Collected Papers of History } \\
\text { Studies }\end{array}$ & 07-11 & 17 \\
\hline 4 & YU Chang-jiang & Hezhe People in the Process of Modernization & $\begin{array}{l}\text { Journal of Guangxi University } \\
\text { for Nationalities (Philosophy } \\
\text { and Social Science Edition) }\end{array}$ & 03-04 & 16 \\
\hline 5 & SHU jingxiang & $\begin{array}{l}\text { A Survey Report on Production and Living } \\
\text { Infrastructure of the Hezhe Ethnic-group }\end{array}$ & $\begin{array}{l}\text { Journal of Helongjiang } \\
\text { National Periodicals }\end{array}$ & $05-10$ & 15 \\
\hline 6 & WU Xiangli & $\begin{array}{l}\text { Strategic Investigation on Protection of Ethnic Culture } \\
\text { Based on the Tourism Exploitation in Small Ethics } \\
\text { Settlement }\end{array}$ & $\begin{array}{l}\text { Journal of Guangxi Ethnics } \\
\text { Study }\end{array}$ & 06-03 & 14 \\
\hline 7 & $\begin{array}{l}\text { Where the Hezhe } \\
\text { Nationality Live } \\
\text { in Compact } \\
\text { Communities }\end{array}$ & $\begin{array}{l}\text { A Survey Report on Advancing the Course of Building } \\
\text { A Well-off Society All-roundly in the Regions }\end{array}$ & $\begin{array}{l}\text { Journal of Helongjiang } \\
\text { National Periodicals }\end{array}$ & 05-04 & 14 \\
\hline 8 & ZHANG Yi-fan & $\begin{array}{l}\text { The Preservation of Intangible Cultural Heritage as } \\
\text { Seen from the Perspective of an Investigation on the } \\
\text { Music of the Hezhe Ethnic-group }\end{array}$ & Musicology in China & 06-04 & 11 \\
\hline 9 & HE Yufang & $\begin{array}{l}\text { Discussion on the Mutuality and Suitability of the } \\
\text { Herzhes. Traditional Culture and the Nature }\end{array}$ & $\begin{array}{l}\text { Journal of Helongjiang } \\
\text { National Periodicals }\end{array}$ & 07-01 & 11 \\
\hline 10 & CUI Yufan & $\begin{array}{l}\text { Research on Intangible Cultural Heritage Status Quo } \\
\text { of the Hezhe Ethnic-group }\end{array}$ & $\begin{array}{l}\text { Journal of Helongjiang } \\
\text { National Periodicals }\end{array}$ & $10-03$ & 10 \\
\hline
\end{tabular}

\subsubsection{Deepening the Academic Research Content}

The research level can be divided into macro and micro, or the basic, applied research and development studies. In the last decade, China's Hezhe research study remained mostly at the macro-level and basic research level, on the other hand, the micro-level, applied and development research relatively remained absent. Therefore, the research content should be deepened while the research level be expanded in order to grasp the essence of Hezhe ethnic and provide effective measures and recommendations to Hezhe cultural heritage and development.

\subsubsection{Lacking in Comparative Analysis}

The purpose of the comparative analysis is commonly used method to reveal the differences and contradictions between things. In recent years, Hezhe comparative research focuses on Hezhe and Nareng, Hezhe and Ainu, Hezhe and Man and so on. The current research is not able to reveal the essence and value of problems. China is a multi-ethnic country. Each ethnic group is a combination of personality and commonality. Personality can be observed through commonality, and vice versa. The two aspects are integrated into one dialectical unity. It could be extracted valuable information and resources from comparative analysis to promote national development. However, the comparative analysis remains a modest sum.

\subsubsection{Stuffless Empirical Research}

The empirical research is the only way to proceed the theoretical studies, while both natural sciences and social sciences need to do empirical research. Researchers collect observations and raise theoretical hypotheses or test theoretical assumptions names empirical research. The current Hezhe study mostly uses it as the main research method, which highlights its strong practical color and provides strong evidence for the ethnic study, but its weakness is the lack of theoretical analysis and thinking, research on the relationship between cause and effect for independent variables and the dependent variable. Empirical research methods are too superficial to reach high academic research.

\subsubsection{Relatively Single Research Perspective}

The present research emphasizes the conversion from a single research perspective to the comprehensive re- 
search perspective. In china, most related research achievements take anthropology or ethnology as a basic research method, focusing on protection and inheritance of the intangible cultural heritage; or relying on social economics to exploit Hezhe area market economy development and discuss social development strategy; or using other perspectives and methods of disciplines to do analysis which is relatively infrequent, leaving too much room to improve.

\subsection{Future Direction of Development}

The way of the survival and development of a nation is determined by its way of life and production from which their own national spirit and integrity can be formed. Once the spirit of the nation has formed, it would become the national standard to judge things (values), guiding the nation's social practice and providing the lasting spiritual motivation for the survival and development of the nation. Professor Wu Xiongwu pointed that the fundamental Chinese spirit is values, because values determine the integration of the national culture, and guide the nation's future development direction [5]. Taking the changing and development of times as the premise for the future development of Chinese nation, the basis of ethnic research has been built by learning the spirit of outstanding achievement from all nations of the world and fostering and building national spirit system.

\subsubsection{Strengthening Awareness of the Problem and Enhancing Targeted Research on Hezhe}

Albert Einstein once said that asking a question is often more important than solving a problem. Because solving a problem may be a mathematical experience or a practical skill, but asking a new question is a new possibility, a new perspective for an old problem, which requires creative imagination and marks real advances in science [6]. In the field of ethnic research, the key point is problematic consciousness. The method of searching, finding, establishing and exploring has the true significance of finding problems, asking questions and solving problems. Such kind of research is more targetable, valuable and significant. During the process of previous research, the lack of problematic consciousness, the vague study object and aimless theme performed as the focus to lead an academic research deformity.

\subsubsection{Broadening the Research Horizons, Enhancing the Level of Ethnic Research}

Observing through the analysis, it should be establish a "viewpoint structure” for Hezhe study in China. Under the guidance of this mode of thinking the various disciplines could form an entirety. It is not just to stay that in the large-scale of anthropological research paradigm the art and history perspective can be based being exclusive of the aesthetic, sociology, ecology scope, which lacks of an overall grasp of the nation and elevation. The procreation of a nation develops and grows under aesthetic art, aesthetic society and aesthetic nature. If it is out of the existence of aesthetic things, it will lose its value and significance.

\subsubsection{Strengthening Comparative Analysis and Empirical Research}

Over the last ten years' research, it shows that the comparative analysis and empirical research of Hezhe in China stays in the scope of the same family with foreign homologous, such as Nareng in Russia and Ainu in Japan. Ethnic Studies emphasize both common problems and deep personality problems. As a multinational country, it should seek the association with the characteristics of each ethnic groups, absorbing the essence and discarding the dregs to achieve the common prosperity development.

\subsubsection{Strengthening Multi-Mode and Promoting Scientific Development of Research}

Ethnic Studies has been based on a number of other disciplines, which requires researchers to expand research ideas, enhance logical rigor and actively learn ideas and methods from other disciplines to achieve the multilevel, multi-angle-depth analysis finally. On research thought, it focuses not only on overall considerations of the status of the current Hezhe study but also on specific analysis of issues of ethnic research level in the different stages. At the same time, it has combined the two aspects closely in order to capture these disciplines' relevance accurately and efficiently to promote multi-mode ethnic studies.

As one of the small ethnic groups, Hezhe undergone thousands of years' vicissitudes, resulting in today's cultural patterns. Though the circumstance without written language made a lot of valuable material and spiritual wealth lost, but did not stop the pace of the national cultural heritage till today. Throughout the academic trends, Hezhe ethnic culture needs to be revived while cultural heritage urgently needs to be inherited. However, 
the true sense of revival and inheritance rather starts from fundamental national education than theory. National education is the fundamental driving force of national development, the catalyst of the cultural heritage. While the key point for establishment and improvement of ethnic education systems is language, without which, none could have a self-contained ethnic education. Currently in China, Hezhe language has already been an endangered language, although many ethnic language scholars and enthusiasts do a great deal of salvage work. The remedial work is still fragmentary not in any systematic manner. Is Hezhe language unable to save the situation? Hezhe is locates in the northeast frontier in China, bordering on Russia. Because of the corruption and incompetence of Qing government, huge tracts of land have been plundered by Czarist Russia. The Sino-Russian Treaty of Aihun split up Hezhe who lived along Heilongjiang River into two parts. Although families have been disrupted the Hezhe language did not stop its steps. According to historical records, Russia started the study on Hezhe earlier than China, and their literature material collection is more complete than China In fact, it is extremely worthy of our reflection at this point [7]. The Miao nationality once has had no written language. Through the efforts of their people, they created their own written language in the fall of 1956, and vigorously promoted it [8]. It perfectly can establish Hezhe language system which is based on Nareng language in Russia to accelerate the process of Hezhe language rather than stagnate and wait or cope with supervising authority's checks. The government of Hezhe inhabited areas should respond to the call of the Party and actively develop the ethnic education in order to speed up the construction of the Hezhe language by training Hezhe language teachers, promoting bilingual education in primary and secondary school and improving the ethnic education system. In this way, the magnificent ethnic culture and precious heritage could be revived and promoted by the development of national industry scientifically and effectively.

\section{References}

[1] Qiu, C. (2005) China National Knowledge Internet and China Knowledge Resource Integrated Database. China Index, Shanghai, 44-46.

[2] China Encyclopedia Dictionary Editorial Committee (1990) China Encyclopedia Dictionary. Huaxia Press, Beijing, 444.

[3] Yan, G.Z. (2012) Business Secret between the Lines: Soft Marketing. Tsinghua University Press, Beijing, 127.

[4] Zhang, C.S., Hu, X.J. and Zhu, X.G. (2003) Medical Information Retrieval Study. Hangzhou Press, Hangzhou, 239.

[5] Wu, X.W. (2004) Chinese National Spirit. Yunnan Nationality Press, Kunming, 57.

[6] (USA) Einstein (2010) Einstein Corpus (Volume Three). Business Press, Beijing, 496.

[7] Sun, Y.M. (2012) China Hezhe Nationality. Ningxia People Press, Ningxia, 27.

[8] He, Z.J. (1999) Data Collection of Miao Study. Liupanshui Data Collection of Miao Study Committee, 72. 
Scientific Research Publishing (SCIRP) is one of the largest Open Access journal publishers. It is currently publishing more than 200 open access, online, peer-reviewed journals covering a wide range of academic disciplines. SCIRP serves the worldwide academic communities and contributes to the progress and application of science with its publication.

Other selected journals from SCIRP are listed as below. Submit your manuscript to us via either submit@scirp.org or Online Submission Portal.
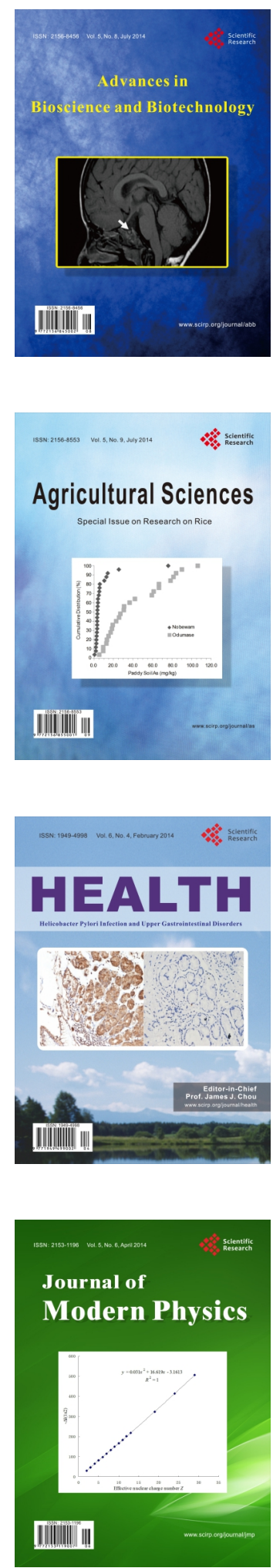
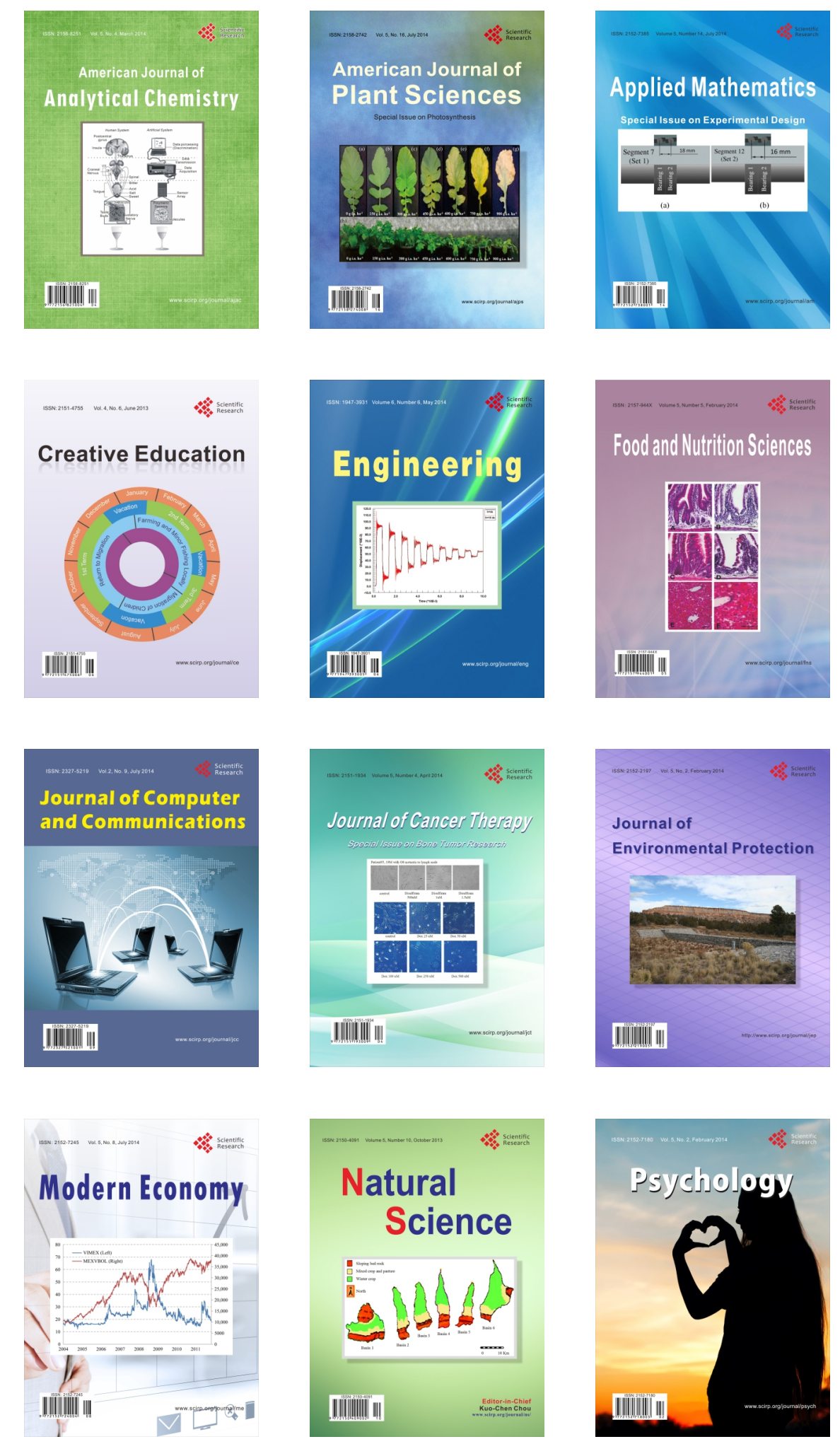